\title{
Are Diagnostic lumbar Medial Branch Blocks Valid? RESULTS OF 2-YEAR FOLLOW-UP
}

\author{
Laxmaiah Manchikanti, MD*, Vijay Singh, MD\#, and Vidyasagar Pampati, MSc*
}

\begin{abstract}
The precise cause of low back pain based on clinical history, physical examination, radiological imaging, and electrophysiological testing can be identified in only $15 \%$ of patients in the absence of disc herniation and neurological deficit. The prevalence of chronic lumbar zygapophysial (facet) joint pain ranges from $15 \%$ to $45 \%$ utilizing comparative local anesthetic blocks in controlled settings in accordance with the criteria established by the International Association for the Study of Pain. Currently, facet joint injection procedures are considered as the gold standard in the diagnosis of facet joint pain.
\end{abstract}

Facet blocks have been criticized as lacking diagnostic validity, along with other tests, including discography, neurophysiologic tests, stress radiographs, $x$-ray stud- ies, bone scintigraphy, thermography and diagnostic ultrasound. However, these assumptions have been based on biased evaluations without consideration of the criteria of the International Association for the Study of Pain, as well as the nature of controlled diagnostic blocks. Utilizing the criteria established by the Agency for Healthcare Research and Quality (AHRQ) for Systems to Rate the Strength of Scientific Evidence, it was shown that the validity, specificity, and sensitivity of facet joint nerve blocks are considered strong in the diagnosis of facet joint pain.

The accuracy of a diagnostic test is best determined by comparing it to an appropriate reference standard, such as biopsy, surgery, autopsy or long-term follow-up. Since we are unable to apply reference standards of biopsy, surgery, or autopsy, and pain relief has been argued as an inconsistent feature, long-term follow-up has been considered as the best indicator.

This study was undertaken to evaluate stability of the diagnosis of lumbar facet joint pain following comparative local anesthetic blocks at a follow-up after 2 years. The results showed that $85 \%$ of the patients available for follow-up withstood the diagnosis of facet joint pain at the end of 2 years, whereas this proportion decreased to $75 \%$, if all the patients in the study were included in the analysis.

Keywords: Facet joint pain, diagnostic blocks, comparative local anesthetic blocks, lidocaine, bupivacaine, false-positive, falsenegative, specificity, sensitivity, accuracy
The prevalence of chronic lumbar zygapophysial (facet) joint pain ranges from $15 \%$ to $45 \%$ (1-8). Kuslich (9) identified facet joints, ligaments, fascia, muscles, intervertebral discs, and nerve root dura as tissues capable of transmitting pain in the low back. Experimental studies have shown lumbar facet joints to be capable of being a source of pain in the low back and referred pain in the lower extremity in normal volunteers (10-16). Anatomically, lumbar facet joints are innervated by the medial branches of the dorsal rami of the spinal nerves from the L1 to L4 and by dorsal ramus of L5 (1723).

Bogduk (16) proposed that blocks of zygapophysial joints can be performed to test the hypothesis that the target joint is the source of a patient's pain by anes-

From *Pain Management Center of Paducah, Paducah, Kentucky and "Pain Diagnostics Associates, Niagara, Wisconsin. Address Correspondence: Laxmaiah Manchikanti, MD, 2831 Lone Oak Road, Paducah, Kentucky 42003. E-mail: drm@apex.net

There was no external funding in preparation of this manuscript. thetizing the target joint. Provocation of pain from a joint is an unreliable criterion, and relief of pain is the essential criterion $(16,24)$. Specificity of lumbar medial branch and L5 dorsal ramus block, as well as the ability of lumbar medial branch blocks to anesthetize zygapophysial joints was demonstrated by Dreyfuss et al (20) and Kaplan et al (21). Bogduk (25) postulated that any structure with a nerve supply capable of causing pain similar to that seen in clinically normal volunteers, which is susceptible to disease or injuries that are known to be painful, can cause pain. In accordance with Bogduk's postulate and in accordance with the criteria established by the International Association for the Study of Pain (26), lumbar zygapophysial (facet) joints have been implicated as the source of chronic pain in $15 \%$ to $45 \%$ of the patients with chronic low back pain. These prevalence studies were conducted utilizing comparative local anesthetic blocks, in which on two separate occasions, the same joint is anesthetized using two local anesthetics with different durations of actions (26-31). The use of comparative local anesthetic blocks has been validated and found to be valid against challenge with placebo $(30,31)$. The comparative local anesthetic blocks also incorporate the fact that a diagnosis cannot be rendered reliably on the basis of a single block. The false-positive rates have been reported to be as high as $47 \%$ (range $22 \%$ to $47 \%$ ), which means that for conditions of low prevalence, out of every three apparently positive responses, two will be false-positive (4-8, 16, 32).

Currently, facet joint injection procedures are considered as the gold standard in the diagnosis of facet joint pain. The popularity of diagnostic facet joint blocks and other precision diagnostic techniques in painful conditions of the spine is due to features like the non-specific character of spinal pain, the irrelevance of radiological findings and the purely subjective character of pain (33). In fact, the precise cause of low back pain based on clinical history, physical examination, radiological testing and electrophysiological testing can be identified only in $15 \%$ of patients in the absence of disc herniation and neurological deficit (34). A multitude of investigators have attempted to correlate 
demographic features, pain characteristics, physical findings, imaging findings and other signs and symptoms with diagnosis of low back pain of facet joint origin (35-41). However, these have been shown to be unreliable in the diagnosis of facet joint pain $(6,16,25,34,41-44)$.

Nachemson and Vingard (45) in evaluation of best-evidence synthesis in assessment of patients with neck and back pain, concluded that various studies outside imaging have rarely demonstrated clinical utility in scientifically admissible studies and, if so, only in small numbers of patients. Ramsey et al (46) found that the evaluation of various diagnostic and treatment devices lacking in scientific regard included facet blocks, discography, and diagnostic nerve root infiltration, along with other tests including neurophysiologic tests, including EMG, stress radiographs, and flexion and extension $\mathrm{x}$ ray studies, bone scintigraphy, thermography, diagnostic ultrasound and temporary external fixation. However, these authors appear to have been involved in a biased evaluation without consideration of the criteria of the International Association for the Study of Pain, as well as the nature of controlled diagnostic blocks. In an Agency for Healthcare Research and Quality (AHRQ) publication of Evidence Report-Technology Assessment, Systems to Rate the Strength of Scientific Evidence, important domains and elements for systems to rate quality of individual articles was described $(47,48)$. For diagnostic test studies, the key domains included study population, adequate description of test, appropriate reference standard, blinded comparison of test and reference, and avoidance of verification bias. Jaeschke et al (49) described that the accuracy of a diagnostic test is best determined by comparing it to the "truth." Accordingly, a publication must assure that an appropriate reference standard (such as biopsy, surgery, autopsy, or long-term follow-up) has been applied to every patient, along with a test under investigation (50). A gold standard or a criterion standard is a method having established a widely accepted accuracy for determining a diagnosis, providing a standard to which a new screening or diagnostic test can be compared. The method need not be a single or simple procedure but could include follow-up of patients to observe the evolution of their conditions or the consensus of an expert panel of clinicians, as is frequently used in the study of psychiatric conditions. Tissue confirmation of the presence of absence of a disease at surgery, with a biopsy, or autopsy, which has served as elegant and accepted gold standard across multiple medical disciplines, is not applicable for interventional pain management. Thus, most pain provocative or relieving tests used to diagnose painful conditions of the spine are more closely related to the physical examination than to a laboratory test (51).

The validity of lumbar facet joint nerve blocks as a gold standard in the diagnosis of lumbar facet joint pain continues to be questioned. Various reference standards applied in surgical situations, such as biopsy, surgery or autopsy, are difficult to apply in diagnosing chronic low back pain of facet joint origin and the pain relief following the diagnostic block, even with relief of pain after provocation following the diagnostic block are looked at with skepticism. Thus, the long-term follow-up appears to be the only standard to be applied in confirming the validity of lumbar facet joint nerve blocks and establishing them as a gold standard.

Dreyfuss et al (52) showed efficacy and validity of radiofrequency neurotomy for chronic lumbar zygapophysial joint pain. They selected patients with controlled diagnostic blocks and also performed electromyography of the multifidus muscle before and after surgery to ensure accuracy of the neurotomy. Thus, they achieved adequate coagulation of the target nerves by carefully placing the electrodes in the correct position as judged radiologically. Essentially, Dreyfuss et al (52) established controlled diagnostic blocks with comparative local anesthetics as a gold standard by means of performing radiofrequency neurotomy. Manchikanti et al (53) in a systematic review of the evidence of medial branch neurotomy in the management of chronic spinal pain, based on combined evidence of radiofrequency neurotomy of medial branches from randomized trials, complimented with nonrandomized trials (prospective and retrospective evaluations) provided strong evidence of short-term relief and moderate evidence of long-term relief of chronic low back pain. Manchikanti et al (54) evaluating the role of therapeutic intraarticular blocks of lumbar facets and lumbar medial branch blocks showed that there was moderate evidence of short-term relief and limited evidence of long-term re- lief of chronic low back pain with intraarticular injections, whereas combined evidence of medial branch blocks from randomized and non-randomized trials provided strong evidence of short-term relief and moderate evidence of long-term relief of chronic low back pain.

This evaluation was undertaken to establish the value and validity of diagnostic facet joint blocks by long-term follow-up.

\section{Methods}

The study was designed to evaluate 44 patients diagnosed with lumbar facet joint pain by controlled comparative local anesthetic blocks. The facet joints were investigated with diagnostic blocks using lidocaine $1 \%$, initially followed by bupivacaine $0.25 \%$ on separate occasions, usually 3 to 4 weeks apart. The mixture of drugs utilized was derived from $2 \%$ lidocaine or $0.5 \%$ bupivacaine by mixing with equal volumes of Sarapin and with or without $2 \mathrm{mg}$ of Depo-Medrol for each $\mathrm{mL}$ of mixture. A definite response was defined as relief of at least $80 \%$ in the symptomatic area. Further, following each block, the patient was examined and previously painful movements were performed.

All the 44 patients were followed for a period of 2 years. They were treated with either therapeutic facet joint nerve blocks or radiofrequency neurotomy. All the patients were followed and evaluated for confirmation of the diagnosis of facet joint pain. If they failed to respond to either radiofrequency neurotomy or medial branch blocks, they were considered negative for facet joint pain. At this time, all the patients considered negative for facet joint pain, received further precision diagnostic blocks to rule out discogenic pain, sacroiliac joint pain, or pain from other structures, followed by appropriate therapeutic modalities.

The evaluation included data collection as to the variables of age, gender, duration of pain in months, nature of onset, height, weight, and history of previous surgical interventions. The quality of pain relief was characterized as less than or greater than $50 \%$ relief. Pain relief greater than $50 \%$ was considered significant, and these patients were characterized as successful with significant pain relief. Pain rating was obtained from a 10point verbal numeric pain rating scale. If the patients responded to the therapeutic interventions directed at the facet joints at 
the end of the 2 years, they were considered to have had a valid diagnosis of facet joint pain without intermittent trauma, etc. If the diagnosis at 2 years was changed, they were considered to be nonfacet joint pain and the diagnosis was apparently a false-positive.

Data was recorded on a database using Microsoft ${ }^{\circledR}$ Access ${ }^{\circledR}$ by a person not participating in the study. The SPSS version 9.0 statistical package was used to generate the frequency tables. Student's t-test was used to test mean significant differences between groups. Categorical data were compared using chi-squared test. Fisher's exact test was used wherever expected value was less than 5. Results were considered statistically significant if the $P$-value was less than 0.05 .

\section{RESULTS}

Of the 44 patients followed at the end of 2 years, 3 patients were lost to follow-up and 2 patients suffered injury, one with fall and the second one with a work related injury resulting in disc herniation and subsequent treatment with other modalities. Of the remaining 39 patients, the diagnosis of lumbar facet joint pain remained at the end of the 2-year period in 33 patients. Six patients failed to respond to therapeutic modalities directed at facet joints in 2 of those patients, we were unable to identify another structure responsible for the pain. The remaining 4 patients were treated for disc related pain. Thus, 33 of the 39 patients $(85 \%)$ followed at the end of 2 years were accurately diagnosed with facet joint pain with comparative controlled diagnostic blocks. However, if the entire sample was taken into consideration, 33 of the 44 patients (75\%), withstood the diagnosis of facet joint pain on long-term follow-up.

We attempted to evaluate the causes of failure of accurate diagnosis with comparative local anesthetic blocks. Thus, we analyzed demographic characteristics of patients, psychological and non-physiological factors and duration of pain relief with each block. Patients with confirmed diagnosis of facet joint pain (positive group) at the end of 2 years were compared with the patients who failed to sustain the diagnosis of facet joint pain (false-positive group) at the end of 2 years. For simplicity purposes and also to have a reasonable number, all the patients (11 of 44) were included in the false-positive group. To avoid any discrepancies, we
Table 1. Demographic characteristics

\begin{tabular}{|c|c|c|c|}
\hline & & $\begin{array}{c}\text { Positive Group } \\
\quad \mathrm{N}=33\end{array}$ & $\begin{array}{l}\text { False-Positive Group } \\
\qquad \mathrm{N}=11\end{array}$ \\
\hline \multirow{2}{*}{ Gender } & Male & $27 \%(9)$ & $64 \%(7)$ \\
\hline & Female & $73 \%(24)$ & $36 \%(4)$ \\
\hline \multicolumn{2}{|c|}{ Age in Years (Mean + SEM) } & $50 \pm 2.4$ & $58 \pm 4.8$ \\
\hline \multicolumn{2}{|c|}{ Height (inches) (Mean + SEM) } & $65 \pm 0.6$ & $68 \pm 1.1$ \\
\hline \multicolumn{2}{|c|}{ Weight (lbs) (Mean \pm SEM) } & $175 \pm 8$ & $188 \pm 14$ \\
\hline \multicolumn{2}{|c|}{ Duration of Pain (months) } & $129 \pm 27$ & $169 \pm 59$ \\
\hline \multirow{2}{*}{ Mode of Onset of Pain } & Following an incident & $36 \%(12)$ & $27 \%(3)$ \\
\hline & Without incident & $64 \%(21)$ & $73 \%(8)$ \\
\hline \multicolumn{2}{|l|}{ Previous Surgery } & $21 \%(7)$ & $36 \%(4)$ \\
\hline \multirow{2}{*}{ Pain Distribution } & Unilateral & $30 \%(10)$ & $45 \%(5)$ \\
\hline & Bilateral & $70 \%(23)$ & $55 \%(6)$ \\
\hline
\end{tabular}

Table 2. Psychological and non-physiological variables

\begin{tabular}{|l|c|c|}
\hline & $\begin{array}{c}\text { Positive } \\
\mathbf{N = 3 3}\end{array}$ & $\begin{array}{c}\text { False-Positive } \\
\mathbf{N = 1 1}\end{array}$ \\
\hline Depression & $70 \%(23)$ & $64 \%(7)$ \\
\hline Generalized Anxiety Disorder & $73 \%(24)$ & $64 \%(7)$ \\
\hline Somatization Disorder & $42 \%(14)$ & $45 \%(5)$ \\
\hline Nonphysiological Symptoms & $15 \%(5)$ & $18 \%(2)$ \\
\hline Nonphysiological Signs & $15 \%(5)$ & $0 \%$ \\
\hline Symptom magnification & $12 \%(4)$ & $0 \%$ \\
\hline
\end{tabular}

Table 3. Duration of pain relief in weeks

\begin{tabular}{|l|c|c|}
\hline & $\begin{array}{c}\text { Positive } \\
\mathbf{N}=\mathbf{3 3}\end{array}$ & $\begin{array}{c}\text { False-Positive } \\
\mathbf{N = 1 1}\end{array}$ \\
\hline Lidocaine Block & $3.1 \pm 0.5$ & $2.7 \pm 0.5$ \\
\hline Bupivacaine Block & $5.6 \pm 0.5$ & $4.6 \pm 0.7$ \\
\hline
\end{tabular}

have analyzed the patients who were lost to follow-up and the patients with re-injury (5 of 44) separately with the 6 patients who failed to respond to therapeutic modalities directed at facet joint pain. There were no significant differences noted among these 2 groups of patients and also when compared with positive group of patients.

Table 1 illustrates the demographic characteristics of all the patients with comparison of age, height, weight, duration of pain, mode of onset of pain, distribution of pain and history of previous surgery. There were no significant differences noted among the positive and falsepositive groups.

Table 2 illustrates psychological and non-physiological variables which included depression, generalized anxiety disorder, somatization disorder, non-physiological symptoms, non-physiological signs and symptom magnification. There were no differences noted in patients who were positive compared to who were false-positive.

Table 3 illustrates the duration of pain relief in weeks following comparative local anesthetic blocks. There were no differences noted among the positive and false-positive population.

\section{Discussion}

This study showed $85 \%$ of the patients followed at the end of the 2 years who were without intervening trauma and who were available at the end of 2 years, withstood the diagnosis of facet joint pain. However, if the entire sample of 44 patients, which also included the patients with re-injury and the patients lost to follow-up, the proportion of patients withstanding the diagnosis of facet joint pain was $75 \%$. Thus, on long-term follow-up of 2 years, it appears that the spec- 
ificity of controlled comparative local anesthetic lumbar medial branch blocks is $75 \%$ to $85 \%$. It also indicates that approximately $15 \%$ to $25 \%$ of the patients following 2 comparative local anesthetic lumbar medial branch blocks may be false-positive.

This study also showed lack of demographic features, psychological and non-physiological variables, and duration of pain relief to identify false-positives from positives. It can be argued that placebo-controlled diagnostic blocks are the most reliable form of controlled blocks. Theoretically, this may be true. However, placebo-controlled diagnostic blocks pose ethical and logistical problems. Further, it has not been proven that placebo-controlled diagnostic blocks are of any more accuracy than comparative local anesthetic blocks. It was shown that $85 \%$ of patients who obtained concordant response to comparative block withstood challenge with placebo (31). While this indicated that comparative blocks were indeed robust, the same study also showed that $65 \%$ of patients who obtained discordant responses also withstood challenge with placebo. Barnsley et al (30) defined concordant response as the one with relief of their pain when either agent was used (lidocaine or bupivacaine). Further, the relief has to be longer when bupivacaine was used. They also defined the discordant response as the one in which patients obtained relief regardless of the agent used (either lidocaine or bupivacaine), but paradoxically, longer-lasting relief occurred when lidocaine was used. The results of long-term follow-up following cervical radiofrequency neurotomy (55) subsequent to placebo-controlled diagnostic blocks was similar to the comparative lumbar radiofrequency neurotomy (52) following comparative local anesthetic blocks. Thus, concordant response to comparative local anesthetic blocks are reliable indicators of a true-positive response, albeit with a $15 \%$ chance of placebo response (56). Thus, $85 \%$ confirmation of the positive diagnosis of facet joint pain at the end of 2 years coincides with previous investigations. However, this will be somewhat lower if $75 \%$ positive rate is considered with all the patients who were not confirmed to be positive for facet joint pain at the end of a 2-year period, even though they were judged falsepositive due to various reasons, including loss of follow-up and the traumatic inci- dents resulting in new pain generators.

The study may be criticized by some stating that placebo-controlled diagnostic blocks or comparative local anesthetic blocks should have been repeated at the end of 2 years. This is not practical as patients may develop learned behavior after 2 years with exposure to previous blockade, behavioral changes following significant pain relief following the previous blocks or radiofrequency neurotomy. And finally, expected duration of relief either with lidocaine or bupivacaine are not known after 2 years in patients exposed to interventional procedures. Thus, considering the limitations of modern medicine, the subjective nature of pain, lack of appropriate understanding of effectiveness of neural blockade, and a multitude of psychological and behavioral issues, long-term follow-up after 2 years with response to treatments is considered as appropriate.

The degree of uncertainty concerning the accuracy of any diagnostic test is defined by the probability of the observed tests results reflect the true nature of the clinical situation under evaluation. The probability that the findings of a given diagnostic test are true and correct can be influenced by a number of factors inherent to the test, including specificity and sensitivity, as well as the clinical setting in which the test is applied. Further, the test itself must also be valid. The test must be reproducible with small measurement errors and little intraobserver and interobserver variability.

Most studies utilized in the diagnosis of low back pain, including history taking and physical examination show methodological shortcomings, such as in terms of clear selection criteria, a clear description of the study population, reproducibility of the index (gold standard) and reference test, blinding of interpretation of the index and reference test results, and prevention of work-up bias (45).

Hildebrandt (33) described that the diagnostic use of neural blockade rests on three premises. First, pathology causing pain is located in an exact peripheral location, and impulses from this site travel via a unique and consistent neural pathway. Second, injection of local anesthetic totally abolishes sensory function of intended nerves and does not affect other nerves. Third, relief of pain after local anesthetic block is attributable solely to block of the target afferent neural pathway. However, the validity of these assumptions is limited by complexities of anatomy, physiology and psychology of pain perception and the effect of local anesthetics on impulse conduction (33). Hogan and Abram (57) also expressed their disappointment with the whole process of diagnostic blockade, along with the prevalence of placebo responses in patients with pain. They believed that placebo response greatly weakens the relevance of studies in which no controlled subjects or blinding was used. False-positive rate (how often patients without a condition will nonetheless have a positive test) and false-negative rate (how often a patient with disease will have a negative test) is extremely crucial because they vary inversely with specificity and sensitivity (57). Specificity is a relative measure of the prevalence of falsepositives, whereas sensitivity is the relative prevalence of false-negative results. The general parameters of accuracy are described as the specificity and sensitivity of the diagnostic test. The most sensitive test will be positive for all cases in which the disease is present. Conversely, the specificity is greatest when there is a positive test result only when the disease is present. Thus, the ideal diagnostic test would have a not only $100 \%$ sensitivity but also $100 \%$ specificity. Since none of the tests available in modern medicine have these ideal features, there is a degree of uncertainty regarding the accuracy of each and every diagnostic test as applied to an individual case. Hildebrandt (33), in a review on the relevance of nerve blocks in treating and diagnosing low back pain, described zygapophysial joint blocks, sacroiliac joint blocks, disc stimulation and nerve root blocks. He concluded that the diagnostic use of neural blockade rests on three premises. First, pathology causing pain is located in an exact peripheral location, and impulses from this site travel via unique and consistent neural route. Second, total abolishment of the sensory function of intended nerves without affecting the other nerves following the injection of local anesthetic. Finally, relief of pain after local anesthetic blocks is attributable solely to the block of the target afferent neural pathway. Even then, the validity of these assumptions is limited by complexities of anatomy, physiology and psychology of pain perception and by the effect of local anesthetics on impulse conduction. Manchikanti et al (48) in preparation of evidence-based practice guide- 
lines for interventional techniques in the management of chronic spinal pain, utilizing strict principles of evidence synthesis in interventional pain management reviewed over 40 publications describing diagnostic blockade or spinal facet joints included a total of 25 studies which met the Agency for Healthcare Research and Quality (AHRQ) criteria, for validity, specifically prevalence, false-positive rate, false-negative rate, provocation response, and role of psychological factors in diagnostic facet joint blocks. They considered that the validity, specificity and sensitivity of facet joint nerve blocks strong in the diagnosis of facet joint pain.

The face validity of medial branch blocks has been established by injecting small volumes of local anesthetic onto the target points and by determining the spread of contrast medium $(20,21)$. Construct validity of lumbar facet joint blocks is also extremely important as placebo effect is the single greatest confounder of diagnostic blocks. Patients are liable to report relief of pain after diagnostic block for reasons other than the pharmacologic action of the drug administered (31). Thus, it is essential to know in every individual case whether the response is a true positive. The theory that testing a patient first with lidocaine and subsequently with bupivacaine provided a means of identifying placebo response has been tested and proven $(1-8,16,20,21,24,30-32,34)$. The specificity of effect of lumbar facet joint blocks was demonstrated in controlled trials $(20,21)$. Further, provocation response was shown to be unreliable and a controlled study (24). The false-negative rate of diagnosis of facet joint blocks was evaluated by Dreyfuss et al (20), which was shown to be $8 \%$ due to unrecognized intravascular injection of local anesthetic. Confounding psychological factors were evaluated by Manchikanti et al (58) showing a lack of influence of psychological factors on the validity of comparative controlled diagnostic local anesthetic blocks of facet joints in the lumbar spine.

Facet joint blockade is achieved either by injection of local anesthetic into the joint space or around the medial branches of the posterior medial rami of the spinal nerves that innervate the joint. There are several problems with intraarticular facet joint injections, mainly failure to enter the joint capsule and rupture of the capsule during the injection. Additionally, there is no physiolog- ical means to test the adequacy of medial branch block, because the lower branches have no cutaneous innervation. Medial branch blocks however are as effective as intraarticular joint blocks when two nerves are infiltrated for one joint. Hildebrandt (33) also concluded that reproducibility of the test is not high, the specificity is only $65 \%$. Further, for diagnosis of facet pain, fluoroscopic control is always necessary as in other precision diagnostic blocks.

While there are no tests utilized in the accurate diagnosis of lumbar facet joint pain, various investigators have evaluated a multitude of tests in the diagnosis of disc herniation and radiculopathy. A formal study has quantified the limitations of conventional concepts in the clinical diagnosis of radicular pain (59). Pain below the knee is not a valid indicator of either radiculopathy, abnormalities on electrodiagnostic studies, or findings of nerve root compression on computerized tomography (CT). Even though it is quite sensitive as a sign of these features, it is very non-specific. Sensitivity and specificity of pain below or above the knee with radiculopathy was 0.90 and 0.28 respectively. Sensitivity and specificity was 0.81 and 0.25 respectively with electrodiagnostics. Correlation with compressive findings on CT was with sensitivity of 0.81 and specificity of 0.28 . In contrast, the correlation between straight leg raising and neurological signs in patients diagnosed clinically as having radicular pain was 0.45 (sensitivity) and 0.82 (specificity) (59). The correlation between straight leg raising and electrodiagnostic features in patients diagnosed clinically as having radicular pain was also similar with sensitivity of 0.35 and specificity of 0.79 .

The evaluation of imaging has been performed extensively. In the investigation of lumbar radicular pain, the objective of medical imaging is to demonstrate cause of pain and its location. Plain radiography does not satisfy this objective. It does not demonstrate nerve roots; it does not demonstrate prolapsed discs. The advent of CT and MRI revolutionized imaging for lumbar radicular pain. The literature on CT and MRI is replete with descriptive publications. It is generally implied that these techniques can provide a definitive diagnosis for virtually any cause of lumbar radicular pain and so, should be used to do so (60). However, these de- scriptive studies do not account for the pre-test probability of various rare conditions, and the limited reliability and validity of CT and MRI in the pursuit of disc herniation. Surprisingly, when compared to surgical findings, CT has an accuracy between $77 \%$ and $92 \%$ and MRI has an accuracy between $76 \%$ and $90 \%$ (61-64). However, this still leaves the question on the validity of the imputation that the disc herniation demonstrated is, indeed, responsible for the patient's symptomatology (60). Studies in asymptomatic volunteers have demonstrated a high prevalence of disc abnormalities (65-67). If the standard is applied that the disc herniation is responsible for patient's symptomatology, the validity of CT and MRI will probably drop significantly. Bogduk and Govind (60) with an evidence-based approach recommended that imaging should be reserved for patients who do not respond to conservative management, or for whom surgery is being contemplated.

Despite the popularity of electrophysiological studies for the investigation of radicular pain, few studies have tested their validity. Bogduk and Govind (68) concluded that for the investigations of patients with acute lumbar radicular pain, electrophysiological tests are not indicated. Multiple studies have found either poor correlation or no diagnostic validity of EMG (69-71).

Thus, the specificity obtained from long-term follow-up of comparative local anesthetic blocks at 2 years appears similar to other investigations including CT and MRI with $75 \%$ to $85 \%$ accuracy. The accuracy of medial branch blocks may be superior, considering that other tests have not been evaluated under the same circumstances.

In summary, this study provided confirmation of positive diagnosis of facet joint pain following comparative local anesthetic blocks at the end of 2 years in $75 \%$ to $85 \%$ of patients. Thus, it provides a specificity of $75 \%$ to $85 \%$ with a sensitivity of $100 \%$.

\section{Conclusion}

Comparative local anesthetic blocks to diagnose lumbar facet joint pain withstood long-term follow-up in $75 \%$ to $85 \%$ of the patients with accurate diagnosis. The accuracy of lumbar medial branch blocks based on long-term follow up is similar or superior to a multitude of well established investigations applied in the 
diagnosis of disc herniation.

\section{ACKNOWLEDGMENTS}

We would like to thank Kim Damron, RN, Carla Beyer, RN, BSN, Renee Barnhill, RN, BSN clinical coordinators; Marla K. Neihoff and Lorie A. Caldwell medical records coordinators; and Tonie Hatton, transcriptionist, for their assistance in preparation of this manuscript.

\author{
Author Affiliation: \\ Laxmaiah Manchikanti, MD \\ Medical Director, \\ Pain Management Center of \\ Paducah, \\ 2831 Lone Oak Road, \\ Paducah, Kentucky 42003 \\ E-mail:drm@apex.net.

\section{Vijay Singh, MD} \\ Medical Director, \\ Pain Diagnostic Associates, \\ 1601 Roosevelt Road, \\ Niagara, WI 54145 \\ E-mail: vsingh@netnet.net.

\section{Vidyasagar Pampati, MSc} \\ Statistician, \\ Pain Management Center of \\ Paducah, \\ 2831 Lone Oak Road, \\ Paducah, Kentucky 42003 \\ E-mail: sagar@painmd.com
}

\section{REFERENCES}

1. Schwarzer AC, Aprill CN, Derby R et al. Clinical features of patients with pain stemming from the lumbar zygapophysial joints. Is the lumbar facet syndrome a clinical entity? Spine 1994; 19:1132-1137.

2. Schwarzer AC, Wang $\mathrm{S}$, Bogduk $\mathrm{N}$ et al. Prevalence and clinical features of lumbar zygapophysial joint pain: A study in an Australian population with chronic low back pain. Am Rheum Dis 1995; 54:100106.

3. Schwarzer AC, Aprill CN, Derby R et al. The relative contributions of the disc and zygapophyseal joint in chronic low back pain. Spine 1994; 19:801-806.

4. Manchikanti L, Pampati VS, Fellows B et al. Prevalence of lumbar facet joint pain in chronic low back pain. Pain Physician 1999; 2:59-64.

5. Manchikanti L, Pampati VS, Bakhit CE et al. The diagnostic validity and therapeutic value of lumbar facet joint nerve blocks with or without adjuvant agents. Cur Rev Pain 2000; 4:337-344.

6. Manchikanti L, Pampati V, Fellows B et al. The inability of the clinical picture to char- acterize pain from facet joints. Pain Physician 2000; 3:158-166.

7. Manchikanti L, Singh V, Pampati V et al. Evaluation of the relative contributions of various structures in chronic low back pain. Pain Physician 2001; 4:308-316.

8. Manchikanti L, Singh V, Pampati VS et al. Is there correlation of facet joint pain in lumbar and cervical spine? An evaluation of prevalence in combined chronic low back and neck pain. Pain Physician 2002; 5:365-371.

9. Kuslich SD, Ulstrom CL, Michael CJ. The tissue origin of low back pain and sciatica: A report of pain response to tissue stimulation during operation on the lumbar spine using local anesthesia. Orthop Clin North Am 1991; 22:181-187.

10. Mooney V, Robertson J. The facet syndrome. Clin Orthop 1976;115:149-156.

11. McCall IW, Park WM, O'Brien JP. Induced pain referral from posterior elements in normal subjects. Spine 1979;4:441-446.

12. Marks R. Distribution of pain provoked from lumbar facet joints and related structures during diagnostic spinal infiltration. Pain 1989;39:37-40.

13. Fukui $S$, Ohseto K, Shiotani $M$ et al. Distribution of referral pain from the lumbar zygapophyseal joints and dorsal rami. Clin J Pain 1997;13:303-307.

14. Hirsch C, Ingelmark BE, Miller M. The anatomical basis for low back pain. Acta Orthop Scand 1963; 33:1-17.

15. Windsor RE, King FJ, Roman SJ et al. Electrical Stimulation Induced Lumbar Medial Branch Referral Patterns. Pain Physician 2002; 5:405-418.

16. Bogduk N. International Spinal Injection Society guidelines for the performance of spinal injection procedures. Part 1: Zygapophysial joint blocks. Clin J Pain;1997;13:285-302.

17. Bogduk N, Wilson AS, Tynan W. The human lumbar dorsal rami. J Anat 1982; 134: 383-397.

18. Bogduk N. The innervation of the lumbar spine. Spine 1983; 8:286-293.

19. Bogduk N, Long D. The anatomy of the so-called "articular nerves" and their relationship to facet denervation in the treatment of low back pain. J Neurosurg 1979; 51:172-177.

20. Dreyfuss P, Schwarzer AC, Lau P et al. Specificity of lumbar medial branch and $\mathrm{L}_{5}$ dorsal ramus blocks: A computed tomography study. Spine 1997; 22:895-902.

21. Kaplan M, Dreyfus P, Halbrook B et al. The ability of lumbar medial branch blocks to anesthetize zygapophysial joint. Spine 1998; 23:1847-1852.

22. Suseki K, Takahashi Y, Takahashi K et al. Innervation of the lumbar facet joints. Spine 1997; 22:477-485.

23. Stilwell DL. The nerve supply of the vertebral column and its associated structures in the monkey. Anat Rec 1956; 125:139169.
24. Schwarzer AC, Derby R, Aprill CN et al. The value of the provocation response in lumbar zygapophysial joint injections. Clin J Pain 1994; 10:309-313.

25. Bogduk N. Low back pain. In Clinical Anatomy of Lumbar Spine and Sacrum, Third edition. Churchill Livingstone, New York, 1997, pp 187-213.

26. Merskey H, Bogduk N. Classification of chronic pain: Descriptions of chronic pain syndromes and definitions of pain terms. Second Edition. IASP Press, Seattle, 1994, pp 180-181.

27. Bonica JJ. Local anesthesia and regional blocks. In Wall PD, Melzack R (eds). Textbook of Pain, Second edition. Churchill Livingstone, Edinburg, 1989, pp 724-743.

28. Bonica JJ, Buckley FP. Regional analgesia with local anesthetics. In Bonica JJ (ed). The Management of Pain. Lea \& Febiger, Philadelphia, 1990; 2:1883-1966.

29. Boas RA. Nerve blocks in the diagnosis of low back pain. Neurosurg Clin North Am 1991; 2:806-816.

30. Barnsley L, Lord S, Bogduk N. Comparative local anesthetic blocks in the diagnosis of cervical zygapophysial joints pain. Pain 1993; 55:99-106.

31. Lord SM, Barnsley L, Bogduk N. The utility of comparative local anesthetic blocks versus placebo-controlled blocks for the diagnosis of cervical zygapophysial joint pain. Clin J Pain 1995; 11:208-213.

32. Schwarzer AC, Aprill CN, Derby R et al. The false-positive rate of uncontrolled diagnostic blocks of the lumbar zygapophysial joints. Pain 1994; 58:195-200.

33. Hildebrandt J. Relevance of nerve blocks in treating and diagnosing low back pain is the quality decisive? Schmerz 2001; 15 : 474-483.

34. Bogduk N. Musculoskeletal pain: Toward precision diagnosis. Progress in pain research and management. In Jensen TS, Turner JA, Wiesenfeld-Hallin Z (eds). Proceedings of the 8th World Congress on Pain. IASP Press, Seattle, 1997, pp 507525.

35. Lilius G, Harilainene A, Laasonen EM et al. Chronic unilateral low-back pain. Predictors of outcome of facet joint injections. Spine 1990; 8:780-782.

36. Lilius G, Laasonen EM, Myllynen P et al. Lumbar facet joint syndrome. Significance of non-organic signs. A randomized placebo-controlled clinical study. Rev Chir Orthop 1989; 7:493-500.

37. Lewinnek GE, Warfield CA. Facet joint degeneration as a cause of low back pain. Clin Orthop 1986; 213:216-222.

38. Helbig T, Lee CK. The lumbar facet syndrome. Spine 1988; 13:61-64.

39. Fairbank JCT, Park WM, McCall IW et al. Apophyseal injection of local anesthetic as a diagnostic aid in primary low back pain syndromes. Spine 1981; 6:598-605.

40. Revel ME, Listrat VM, Chevalier XJ et al. Facet joint block for low back pain. Identi- 
fying predictors of a good response. Arch Phys Med Rehabil 1992; 73:824-828.

41. Revel M, Poiraudeau S, Auleley GR et al. Capacity of the clinical picture to characterize low back pain relieved by facet joint anesthesia. Proposed criteria to identify patients with painful facet joints. Spine 1998; 23:1972-1977.

42. Schwarzer AC, Derby R, Aprill CN et al. Pain from the lumbar zygapophysial joints: A test of two models. J Spinal Disord 1994;7:331-336.

43. Schwarzer AC, Wang SC, O'Driscoll D et al. The ability of computed tomography to identify a painful zygapophysial joint in patients with chronic low back pain. Spine 1995; 20:907-912.

44. Schwarzer AC, Scott AM, Wang SC et al. The role of bone scintigraphy in chronic low back pain: A comparison of SPECT and planar images and zygapophysial joint injection. Aust NZJ Med 1992; 22:185.

45. Nachemson AL, Vingoöard E. Assessment of patients with neck and back pain. In Nachemson AL, Johnson E (eds). Neck and Back Pain. Lippincott, Williams and Wilkins, Philadelphia, 2000, pp 189-236.

46. Ramsey SD, Luce BR, Deyo R et al. The limited state of technology assessment for medical devices: Facing the issues. Am J Managed Care 1998; 4:188-199.

47. Systems to rate the strength of scientific evidence. Evidence Report/Technology Assessment No. 47 University of North Carolina: Agency for Healthcare Research and Quality. AHRQ Publication No. 02E015; 2002.

48. Manchikanti L, Heavner J, Racz G et al. Methods for evidence synthesis in interventional pain management. Pain Physician 2003; 6:89-111.

49. Jaeschke R, Guyatt G, Lijmer J. Diagnostic tests. In Guyatt G, Rennie D (eds). Users' Guides to the Medical Literature - A Manual for Evidence-Based Clinical Practice. AMA Press, Chicago, 2002; pp 121-140.

50. Sackett DL, Haynes RB, Guyatt GH et al.
Clinical Epidemiology, A Basic Science for Clincial Medicine. $2^{\text {nd }}$ Ed. Little, Brown and Company, Boston, 1991; pp 53-57.

51. Saal JS. General principles of diagnostic testing as related to painful lumbar spine disorders. Spine 2002; 27:2538-2545.

52. Dreyfuss P, Halbrook B, Pauza K et al. Efficacy and validity of radiofrequency neurotomy for chronic lumbar zygapophysial joint pain. Spine 2000; 25:1270-1277.

53. Manchikanti L, Singh V, Vilims B, Hansen $\mathrm{H}$, Schultz D, Kloth D. Medial branch neurotomy in management of chronic spinal pain: Systematic review of the evidence. Pain Physician 2002; 5:405-418.

54. Manchikanti L, Staats P, Singh V et al. Evidence-based practice guidelines for interventional techniques in the management of chronic spinal pain. Pain Physician 2003; 6:3-87.

55. Lord SM, Barnsley L, Wallis BJ et al. Percutaneous radio-frequency neurotomy for chronic cervical zygapophyseal-joint pain. N Eng J Med 1996; 335:1721-1726.

56. Bogduk N, Lord SM. Cervical zygapophysial joint pain. Neurosurgery Quarterly 1998; 8:107-117.

57. Hogan QH, Abram SE. Neural blockade for diagnosis and prognosis. Anesthesiology 1997; 86:216-241.

58. Manchikanti L, Pampati V, Fellows B et al. Influence of psychological factors on the ability of diagnose chronic low back pain of facet joint origin. Pain Physician 2001; 4:349-357.

59. Haldeman S, Shouka M, Robboy S. Computed tomography, electrodiagnostic and clinical findings in chronic workers' compensation patients with back and leg pain. Spine 1988; 13:345-350.

60. Bogduk N, Govind J. Imaging. In Medical Management of Acute Lumbar Radicular Pain: An Evidence-Based Approach. Cambridge Press, Newcastle 1999, pp 43-51.

61. Herzog RJ. The radiologic assessment for a lumbar disc herniation. Spine 1996; 21: 19S-38S.
62. Forristal RM, Marsh HO, Pay NT. Magnetic resonance imaging and contrast $\mathrm{CT}$ of the lumbar spine: Comparison of diagnostic methods and correlation with surgical findings. Spine 1988; 13:1049-1054.

63. Fries JW, Abodeely DA, Vijungco JG et al. Computed tomography of herniated and extruded nucleus pulposus. J Comput Assist Tomogr 1982; 6:874-887.

64. Albeck MJ, Hilden J, Kjaer L et al. A controlled comparison of myelography, computed tomography, and magnetic resonance imaging in clinically suspected lumbar disc herniation. Spine 1995; 20:443448.

65. Wiesel SW. A study of computer-assisted tomography. 1. The incidence of positive CAT scans in an asymptomatic group of patients. Spine 1986; 9:549-551.

66. Boden SD, Davis DO, Dina TS et al. Abnormal magnetic-resonance scans of the lumbar spine in asymptmoatic patients. J Bone Joint Surg 1990; 72A:403-408.

67. Jensen MC, Bran-Zawadski MN, Obuchowski $\mathrm{N}$ et al. Magnetic resonance imaging of the lumbar spine in people without back pain. N Engl J Med 1994; 331:6973.

68. Bogduk N, Govind J. Electrophysiological Studies. In Medical Management of Acute Lumbar Radicular Pain: An EvidenceBased Approach. Cambridge Press, Newcastle 1999, pp 53-58.

69. Tonzola RF, Ackil AA, Shahani BT et al. Usefulness of electrophysiological studies in the diagnosis of lumbosacral root disease. Ann Neurol 1981; 9:305-308.

70. Tullberg T, Svanborg E, Isacsson J et al. A preoperative and postoperative study of the accuracy and value of electrodiagnosis in patients with lumbosacral disc herniation. Spine 1993; 18:837-842.

71. La Joie WJ. Nerve root compression: Correlation of electromyographic, myelographic and surgical findings. Arch Phys Med Rehab 1972; 53:390-392. 